\title{
Reliability and Validity of the Persian Version of Amphetamine Cessation Symptom Assessment (ACSA) Questionnaire in Iran
}

\author{
Yousef Khani,, ${ }^{1}$ Saharnaz Nedjat, ${ }^{2}$ Mahshid Mojtahedzadeh Faghihi, ${ }^{3}$ Abolfazl Mollajan, ${ }^{1}$ and Shahnaz \\ $\operatorname{Rimaz}{ }^{4, *}$ \\ ${ }^{1}$ Alborz University of Medical Sciences, Karaj, IR Iran \\ ${ }^{2}$ Department of Epidemiology and Biostatistics, School of Public Health, Tehran University of Medical Sciences (TUMS), Tehran, IR Iran \\ ${ }^{3}$ Department of Clinical Psychology, Kharazmi University, Karaj, IR Iran \\ ${ }^{4}$ Radiation Biology Research Center, Department of Epidemiology, School of Public Health, Iran University of Medical Sciences (IUMS), Tehran, IR Iran \\ "Corresponding author: Shahnaz Rimaz, Radiation Biology Research Center, Department of Epidemiology, School of Public Health, Iran University of Medical Sciences (IUMS), \\ Tehran, IR Iran. E-mail: srimaz2000@yahoo.com
}

Received 2015 July 27; Revised 2016 March 27; Accepted 2016 December 06.

\begin{abstract}
Background: Illegal use of psychotropic drugs has become a great problem around the world. Change in the traditional pattern of drug abuse to industrial drugs is one of the challenges faced today in Iran.

Objectives: The present study was performed to determine the reliability and validity of the Persian version of the amphetamine cessation symptom assessment (ACSA) questionnaire in patients of residential medical center in Alborz province of Iran.

Patients and Methods: In this cross-sectional study, 106 patients accepted to participate from patients enrolled in the residential medical center of Alborz province. After the questionnaire was translated to Persian, face, content, and construct validity was assessed. Exploratory factor analysis and principal component analysis were used to assess the construct validity. Content validity index (CVI) was used to assess the content validity of the questionnaire. In order to determine the reliability of the questionnaire, internal consistency method with Cronbach's alpha coefficient was used. The face validity step was based on the opinion of experts and patients that had just withdrew from the study and limited changes were inserted in the questionnaire.

Results: Content validity for the entire of questionnaire was $86.5 \%$ and for questions individually was $80 \%$ and higher. In factor analysis 3 acceptable factors with higher than 1 were identified that justified $65.81 \%$ of the entire variance. The Cronbach's alpha coefficient for the entire questionnaire was $84 \%$, and also for the first, second, and third factor this was $91 \%, 77 \%$, and $96 \%$, respectively. Conclusions: Results of this study showed that the questionnaire had appropriate reliability and validity in the evaluation of amphetamine withdrawal symptoms and could be used in similar activities and studies in Iran.
\end{abstract}

Keywords: Amphetamine, Validity, Reliability, Factor Analysis

\section{Background}

Illegal use of psychotropic drugs has become a great problem around the world (1). According to the statistics from the united nations office on drugs and crime in 2014, the abuse of amphetamine compounds has been an increasing epidemic. According to this report, the number of amphetamine compound-producer laboratories has increased from 12,567 in 2011 to 14,322 in 2012. This paper reported that 35 million people all over the world use amphetamine compounds regularly. Iran was introduced as a country with an increasing rate of abuse and production of amphetamine compounds (2). Illicit drug use in Iran and associated problems have been present for a long time in the Iranian society (3). Historically, in Iran recreational drug abuse dates back to the 17th century (4). Iran is currently facing a transition from traditional drugs to the industrial production of illicit drugs, including amphetamines. The abuse of these materials in pre- vious decades was negligible, yet is increasing in the recent years (5). According to a recent study using the rapid situation assessment (RSA) of drug abuse in Iran, the frequency of amphetamine use makes up 5.2\% of the total drug abuse frequency (6). Other studies have reported that amphetamine use occurs in $18.5 \%$ of young adults aged 15 to 25 years, living in Tehran city (7), 4.3\% of Birjand and Gilan university students, and $11 \%$ of students of Hamedan universities (8-10). Reasons for the abuse of drugs may be the low price of industrial materials, easy access, and the increasing price of traditional opiates (11). Investigations have shown that parallel to the increasing abuse of such drugs, there has been an increase in the demand for treatment (12). A questionnaire with proper validity and reliability is an important part of a good treatment plan. Withdrawal symptoms occur in individuals with an established history of drug use. McGregor et al. indicate that the most important step in the effective treatment of addicts of 
amphetamine compounds is determining the time-course and severity of withdrawal symptoms making the timely implementation of appropriate interventions easier to target specific symptoms (13).

Observed symptoms of amphetamine withdrawal could include fatigue, drowsiness, depression, aggression, disorder, excitability, pain, lack of enjoyment, and reduction in concentration (14-18). Unfortunately, most studies investigating amphetamine withdrawal processes lack adequate sample size or include participants, who are experiencing simultaneous drug withdrawal interactions potentially creating confounding results. Additionally, most studies lack the use of a validated scale measure to evaluate withdrawal symptoms $(15,19)$. Several questionnaires are currently available to measure symptoms of amphetamine withdrawal, including the amphetamine withdrawal questionnaire (AWQ) (20), the severity of amphetamine dependence questionnaire (SAMDQ) (21), and the amphetamine cessation symptoms assessment (ACSA) (13). The ACSA was designed by McGregor et al. by combining AWQ and the Cocaine selective severity assessment questionnaire (CSSA) (22). The new measure purports to assess withdrawal symptoms more accurately, and its validity and reliability have been proved in assessment and evaluation of amphetamine abuse withdrawal symptoms (13). The present study was done to determine the reliability and validity of Persian Version of amphetamine cessation symptom assessment (ACSA) questionnaire in patients of residential medical center in Alborz province of Iran.

\section{Patients and Methods}

A cross sectional study was completed using the ACSA (13). The ACSA evaluates 3 factors over 16 questions, including anxiety and mood (11), fatigue (3), and amphetamine craving (2). The Persian-version of the ACSA questionnaire was translated from English to Persian language and proofed using the backward-forward translation method (23). To explore the face validity of the questionnaire, 10 experts provided direction for the writing, translating, and arrangement of questions. A group discussion was facilitated through individual sessions where amphetamine withdrawal symptoms were discussed and the questionnaire was provided. While the translated ACSA contributed to minor changes in wording, no question was deleted or added. Patients in residential medical center of the Alborz province of Iran, provided treatment for amphetamine withdrawal, were enrolled in this study. All participants in the study were male. The inclusion criteria in this study required participants to be male being at least 15 years old, having been diagnosed with amphetamine dependence as listed in the DSM-IV, and having provided positive urine test for amphetamine compounds. Also, Psychotic patients, patients with acute medical diseases requiring psychotherapy, and patients, who were hospitalized for issues related to opiates use were excluded from this study. A factor analysis was used to assess this study's validity, allowing use of a sample size between 100 and 200 participants (24).

One-hundred and six individuals that received care at the residential medical center of Alborz province were enrolled in the study through the convenience sampling method. An informed consent form was completed by all participants. Exploratory factor analysis and principal component analysis were used to assess construct validity. Cronbach's alpha was used to assess the internal reliability of the questionnaire. The questionnaire was given to experts working in the field of amphetamine abuse. Experts graded each question's relevance to amphetamine withdrawal symptoms by assigning 1 of 3 valuations a) not related, b) a little related, c) greatly related, and d) completely related. A content validity index (CVI) was used to assess the content validity of the questionnaire. In the first method, a CVI index was calculated for the overall questionnaire. The number of questions identified by each expert as completely related or greatly related was divided by all questions and the result was translated to a percentage: the average of all summed expert percentages was then calculated. In the second method, CVI was calculated for each question, where each question was assigned one point by each expert that qualified it as completely related or greatly related to assessing amphetamine withdrawal. The total points for each question were then summed and divided by the total number of scoring experts to generate a percentage (25).

Kaiser-Meyer-Olkin's sampling adequacy index and Bartlett's test of sphericity were used to determine which factor analysis method was appropriate for data computation. Analyses were completed using SPSS software version 16.

\section{Results}

One-hundred and six male patients were enrolled in this study. The average and median age of participants was 31.14 and 30, respectively. Of the total participants, $24.53 \%$ were married, $23.59 \%$ were divorced, and $51.88 \%$ were single. Overall, $1.89 \%$ of the participants were illiterate, $15.09 \%$ had elementary education, $37.74 \%$ had some level of formal schooling, 36.79\% had obtained a diploma, and $8.49 \%$ had advanced academic education. Demographic features of these people are presented in Table 1 . 
Table 1. Studied Population Distribution Based on Demographic Features ( $N=106)$

\begin{tabular}{|c|c|c|}
\hline & & No. (\%) \\
\hline \multirow{5}{*}{ Age } & $20>$ & $7(6.6)$ \\
\hline & $20-30$ & $52(49.06)$ \\
\hline & $30-40$ & $36(33.96)$ \\
\hline & $40-50$ & $9(8.49)$ \\
\hline & $>50$ & $2(1.89)$ \\
\hline \multirow{3}{*}{ Marital status } & Married & $26(24.53)$ \\
\hline & Divorced & $25(23.59)$ \\
\hline & Single & $55(51.88)$ \\
\hline \multirow{5}{*}{ Education level } & Illiterate & $2(1.89)$ \\
\hline & Elementary school & $16(15.09)$ \\
\hline & Guidance school & $40(37.74)$ \\
\hline & Diploma & 39 (36.79) \\
\hline & Academic education & $9(8.49)$ \\
\hline \multirow{6}{*}{ Ethnics } & Turkish & $29(27.36)$ \\
\hline & Persian & $37(34.91)$ \\
\hline & Kord & $21(19.81)$ \\
\hline & Lor & $15(14.15)$ \\
\hline & Baloch & $1(0.94)$ \\
\hline & Turkmen & $3(2.83)$ \\
\hline \multirow{2}{*}{ Employment status } & Employed & $65(61.32)$ \\
\hline & Unemployed & $41(38.68)$ \\
\hline
\end{tabular}

Participants reported no problems responding to the Persian version of the ASCA, and both patients being treated for amphetamine withdrawal and administrators appeared engaged during the questionnaires administration. Face validity was demonstrated through both patients and administrators reporting that the questionnaire addressed amphetamine withdrawal (26). Content validity index (CVI) for the overall questionnaire was $87.5 \%$, and was $80 \%$ or higher for each individual question. Results demonstrated adequate sampling index (KaiserMeyer-Olkin) at 0.79 and Bartlett's test of sphericity was significant $(\mathrm{P}<0.001)$. According to both criteria, it could be concluded that an appropriate factor analysis was applied for this study (24). Specific value index and the variance determination percentage were used to determine that evaluation of amphetamine withdrawal symptoms constituted of several components. All reliability and validity for the Persian version of the ASCA $65.80 \%$ was justified by $5.99,2.27$, and 2.26 loading factors, respectively. The justified variance for the first, second, and third factor was $37.44 \%, 14.22 \%$, and $14.14 \%$, respectively (Table 2 ).
Table 2. Determined Variance by Factors Total Squares of Rotated Functional Loads

\begin{tabular}{lccc}
\hline Factors & Specific Value & $\begin{array}{c}\text { Justified } \\
\text { Variance, } \%\end{array}$ & $\begin{array}{c}\text { Accumulative } \\
\text { Percentage of } \\
\text { Justified } \\
\text { Variance }\end{array}$ \\
\hline First factor & 5.99 & $37 / 44$ & $37 / 44$ \\
\hline Second factor & 2.27 & $14 / 14$ & $51 / 58$ \\
\hline Third factor & 2.26 & $14 / 22$ & $65 / 80$ \\
\hline
\end{tabular}

To select questions, functional loads higher than 0.4 were accepted (26). According to the results of the rotated component matrix, 11 questions loaded on the first factor $(1,3,4,5,78,10,11,12,13$, and 14), 3 questions loaded on the second factor $(2,6,9)$, and 2 questions (15 and 16) loaded on the third factor. Labeling for the factors was completed based on the original questionnaire. First, second, and third factors were named by anxiety and mood, fatigue, and craving for use of amphetamine, respectively (Table 3).

Assessment of reliability was done for the entire group and individually for each of the 3 factors. Cronbach's alpha coefficient for the entire and for the individual factors of anxiety and mood, fatigue, and craving for use of amphetamine was $91 \%, 77 \%$, and $96 \%$, respectively (Table 4 ).

\section{Discussion}

When a questionnaire is translated for use with a different society and culture, it is necessary to examine its validity and reliability $(27,28)$. In this study, the face, content, and construct validity and reliability of the Persian version of ASCA questionnaire was examined. Results demonstrated that this version of the questionnaire had appropriate validity and reliability and that the questions retained their relevance for involved participants (26). Content validity was appropriate, and this version of the questionnaire appeared to assess symptoms and natural processes of amphetamine withdrawal. Factor analysis appeared to be the best application for assessment of this questionnaire's construct validity, exploring internal consistency of many variables while classifying them to general factors (25). Through factor analysis, 3 factors were determined for the Persian version of the ACSA questionnaire. These results were consistent with that of McGregor et al. (2008). The 3 factors justified $65.8 \%$ of the overall variance between question responses. Variance for the first (anxiety and mood), second (fatigue), and third (craving) factor were $37.44 \%, 14.14 \%$, and $14.22 \%$, respectively. Findings of the current study are relatively consistent with that of McGregor et al., who found 3 factors comprised $64.7 \%$ of the overall variance. Individually, the first, second, and third 
Table 3. Rotated Component Matrix for Questions

\begin{tabular}{|c|c|c|c|}
\hline Questions & First Factor & Second Factor & Third Factor \\
\hline $\begin{array}{l}\text { 1- Have you had } \\
\text { difficulty } \\
\text { concentrating? (e.g., } \\
\text { on reading, } \\
\text { conversation, tasks, or } \\
\text { making plans) }\end{array}$ & 0.71 & 0.12 & 0.10 \\
\hline $\begin{array}{l}\text { 2- Have you been } \\
\text { sleeping (or wanting } \\
\text { to sleep) a lot? }\end{array}$ & 0.14 & 0.04 & 0.90 \\
\hline $\begin{array}{l}\text { 3- Have you been } \\
\text { tense? }\end{array}$ & 0.75 & 0.09 & 0.25 \\
\hline $\begin{array}{l}\text { 4- Have you had vivid, } \\
\text { unpleasant dreams? }\end{array}$ & 0.63 & 0.03 & 0.23 \\
\hline $\begin{array}{l}\text { 5- Have you felt } \\
\text { irritable? }\end{array}$ & 0.76 & 0.13 & 0.19 \\
\hline $\begin{array}{l}\text { 6- Have you been } \\
\text { tired? }\end{array}$ & 0.08 & 0.04 & 0.94 \\
\hline $\begin{array}{l}\text { 7- Have you been } \\
\text { agitated? }\end{array}$ & 0.85 & 0.13 & 0.00 \\
\hline $\begin{array}{l}\text { 8- Have you felt that } \\
\text { life is not worth } \\
\text { living? }\end{array}$ & 0.67 & 0.15 & 0.26 \\
\hline $\begin{array}{l}\text { 9- How active have you } \\
\text { been compared to } \\
\text { your usual level of } \\
\text { activity? }\end{array}$ & 0.08 & 0.11 & 0.71 \\
\hline $\begin{array}{l}\text { 10- Have you felt } \\
\text { anxious? }\end{array}$ & 0.79 & 0.06 & 0.02 \\
\hline $\begin{array}{l}\text { 11- Have you lost } \\
\text { interest in things or } \\
\text { no longer take } \\
\text { pleasure in them? }\end{array}$ & 0.68 & 0.23 & 0.03 \\
\hline $\begin{array}{l}\text { 12- Have you found it } \\
\text { difficult to trust other } \\
\text { people? }\end{array}$ & 0.79 & 0.02 & 0.05 \\
\hline 13- Have you felt sad? & 0.68 & 0.08 & 0.02 \\
\hline $\begin{array}{l}\text { 14- Have you felt as if } \\
\text { your movements were } \\
\text { slow? }\end{array}$ & 0.86 & 0.01 & 0.10 \\
\hline $\begin{array}{l}\text { 15- In the past } 24 \\
\text { hours, how much TIME } \\
\text { have you spent } \\
\text { craving for } \\
\text { amphetamines? }\end{array}$ & 0.06 & 0.93 & 0.13 \\
\hline $\begin{array}{l}\text { 16- How STRONG are } \\
\text { your cravings for } \\
\text { amphetamines? }\end{array}$ & 0.05 & 0.93 & 0.12 \\
\hline
\end{tabular}

factor justified $45 \%, 10.1 \%$, and $9 \%$ of the total variance, respectively. The results of the current study showed that the first factor covered questions 1 (problem in concentration), 3 (excitement), 4 (unpleasant nightmares), 5 (getting angry), 7 (agitation), 8 (suicide thoughts), 10 (anxiety), 11 (lack of enjoying life), 12 (suspicion), 13 (sadness), and 14 (slow movements), the second factor covered questions
2 (drowsiness), 6 (feeling fatigue), and 9 (non-activity), and the third factor coversed questions 15 (craving) and 16 (severity of craving). The results of the current study are consistent with those of McGregor et al. (16). However, there are some differences between results of the current study and the results of reference questionnaire's designers so that in the current study, the aspect of craving justifies the greatest percentage of variance, followed by fatigue, yet in McGregor's study, aspect of fatigue justified the greatest percentage of variance, followed by craving. A possible reason for this difference might be due to behavioral differences among the participators in both studies and difference in the justifiable sample. In this study, total internal consistency and also all 3 factors were examined by Cronbach's alpha coefficient. Internal consistency for the entire questionnaire was $84 \%$ and for anxiety and mood, fatigue, and craving, these were $91 \%$, $77 \%$, and $96 \%$, respectively. The Cronbach's alpha coefficient showed the high consistency of the Persian version of this questionnaire (Cronbach's alpha $=84 \%$, high consistency $=$ more than $80 \%$ ) (29). Therefore, it could be concluded that the reliability of the Persian version of this questionnaire was appropriate. Also, the Cronbach's alpha coefficient in the study of the reference questionnaire for the entire questionnaire was $76 \%$, and for the first, second, and third factor, this was $77 \%, 82 \%$, and $92 \%$, respectively (13). These differences may be explained by cultural and population differences and also translation procedures (26).

\subsection{Conclusions}

The results of this study demonstrated that the Persian version of amphetamine cessation symptom assessment questionnaire had appropriate validity and reliability and had usability in related studies and activities in Iran. Hence, it is recommended for researchers and therapists, who work in the addiction field, to seek use of this questionnaire in amphetamine withdrawal treatments.

\section{Acknowledgments}

This study was adopted from an MSc thesis from Tehran University of Medical Science (school of public health). Therefore, the authors appreciate all professors, who accepted to revise the face validity and modify the questionnaire. Moreover, the authors appreciate all personnel and patients at the residential medical center of Alborz province.

\section{Footnote}

Authors' Contribution: Funding for thesis,desigh, Drafting, analysis and interpretation of data and Critical re- 
Table 4. Reliability Coefficient (Cronbach's alpha) of AWS Questionnaire Generally and Individually

\begin{tabular}{|c|c|c|c|c|}
\hline & Total & Anxiety and mood & Fatigue & Craving \\
\hline Cronbach's alpha & 0.84 & 0.91 & 0.77 & 0.96 \\
\hline
\end{tabular}

vision of the manuscript for important intellectual content: Yousef Khani; Study concept, design and Administrative, technical, and material support: Saharnaz Nedjat and Shahnaz Rimaz; Acquisition of data: Mahshid Mojtahedzadeh Faghihi; Statistical analysis: Shahnaz Rimaz

\section{References}

1. Costa e Silva JA. Evidence-based analysis of the worldwide abuse of licit and illicit drugs. Hum Psychopharmacol. 2002;17(3):131-40. doi: 10.1002/hup.378. [PubMed: 12404690$]$.

2. ADR. World Drug Report. ; 2014.

3. Mohamadi K. Survey the changing pattern of drug use than the traditional (low risk) to industrial(high risk) of Iran. The Second Conference of Social and Culture Pathologies. .

4. Moharreri MR. General View of Drug Abuse in Iran and a One-Year Report of Outpatient Treatment of Opiate Addiction in the City of Shiraz. NIDA research monograph. 1978;19:69-81.

5. Mokri A. Brief overview of the status of drug abuse in Iran. Arch Iranian Med. 2002;5(3):184-90.

6. Narenjiha H, Rafiey H, Baghestani AH. Rapid situation assessment of drug abuse and drug dependence in Iran. ; 2005.

7. Barooni S, Mehrdad R, Akbari E. A survey of Ecstasy use among 1525 year-olds in five areas of Tehran. Tehran Univ Med J TUMS Pub. 2008;65(11):49-54

8. Moasheri N, Miri M, Moghadam HRM, Eslami MR. A Study of Birjand University students' knowledge and attitude towards taking Ecstasy pills. J Birjand Univ Med Sci. 2006;13(4):9-15.

9. Mohtasham-Amiri Z, Jafari-Shakib A, Khalili-Moosavi A. Prevalence and factors associated with Ecstasy use among college undergraduates in north of Iran-2005. Asian J Psychiatr. 2011;4(1):31-4. doi: 10.1016/j.ajp.2011.01.004. [PubMed: 23050911].

10. Barati M, Allahverdipour H, Jalilian F. Prevalence and predictive factors of psychoactive and hallucinogenic substance abuse among college students. J Fund Ment Health. 2012;13(4):374-83.

11. Nadery S, Sefatian S, Binazadeh M. Comprehensive textbook of addiction treatment. 1. Iranian National Drug Control Headquarters; 2008.

12. Jenner L, McKetin R. Prevalence and patterns of psychostimulant use. Models of intervention and care for psychostimulant users. 2nd ed. National Drug Strategy Monograph Series. ; 2004.

13. McGregor C, Srisurapanont M, Mitchell A, Longo MC, Cahill S, White JM. Psychometric evaluation of the Amphetamine Cessation Symptom Assessment. J Subst Abuse Treat. 2008;34(4):443-9. doi: 10.1016/j.jsat.2007.05.007. [PubMed:17629443].
14. Angrist B, Sudilovsky A. Stimulants. Springer; 1978. pp. 99-165.Central nervous system stimulants: historical aspects and clinical effects.

15. Cantwell B, McBride AJ. Self detoxication by amphetamine dependent patients: a pilot study. Drug Alcohol Depend. 1998;49(2):157-63. [PubMed: 9543652].

16. Monroe RR, Drell HJ. Oral use of stimulants obtained from inhalers.J Am Med Assoc. 1947;135(14):909-15. [PubMed: 18897598].

17. Hawks D, Mitcheson M, Ogborne A, Edwards G. Abuse of methylamphetamine. BrMed J. 1969;2(5659):715-21. [PubMed: 5786759].

18. Newton TF, Kalechstein AD, Duran S, Vansluis N, Ling W. Methamphetamine abstinence syndrome: preliminary findings. Am J Addict. 2004;13(3):248-55. doi: 10.1080/10550490490459915. [PubMed: 15370944].

19. Schuckit MA, Smith TL, Daeppen JB, Eng M, Li TK, Hesselbrock VM, et al. Clinical relevance of the distinction between alcohol dependence with and without a physiological component. Am J Psychiatry. 1998;155(6):733-40. doi: 10.1176/ajp.155.6.733. [PubMed: 9619144].

20. Srisurapanont M, Jarusuraisin N, Jittiwutikan J. Amphetamine withdrawal: I. Reliability, validity and factor structure of a measure. Aust N Z J Psychiatry. 1999;33(1):89-93. doi:10.1046/j.1440-1614.1999.00517.x. [PubMed: 10197890].

21. Churchill AC, Burgess PM, Pead J, Gill T. Measurement of the severity of amphetamine dependence. Addiction. 1993;88(10):1335-40. [PubMed: 8251870].

22. Kampman KM, Volpicelli JR, McGinnis DE, Alterman AI, Weinrieb RM, D'Angelo L, et al. Reliability and validity of the Cocaine Selective Severity Assessment. Addict Behav. 1998;23(4):449-61. [PubMed: 9698974].

23. Organization WH . Process of translation and adaptation of instruments. World Health Organization; 2010.

24. Plichta SB, Kelvin EA, Munro BH. Munro's statistical methods for health care research. Wolters Kluwer Health/Lippincott Williams \& Wilkins; 2013.

25. Waltz CF, Strickland OL, Lenz ER. Measurement in nursing and health research. Springer Publishing Company; 2010.

26. Alavi SS, Jannatifard F, Eslami MR, Rezapour H. Survey on validity and reliability of diagnostic questionnaire of internet addiction disorder in students users. Zahedan J Res Med Sci. 2011;13(7):34-8.

27. Hillen MA, Butow PN, Tattersall MH, Hruby G, Boyle FM, Vardy J, et al. Validation of the English version of the Trust in Oncologist Scale (TiOS). Patient Educ Couns. 2013;91(1):25-8. doi: 10.1016/j.pec.2012.11.004. [PubMed: 23219483].

28. Michaeli Manee F. Internal consistency and confirmatory factor analysis of Wells and Davis Thought control questionnaire. Iran J Psychiatr Clin Psychol. 2011;16(4):468-78.

29. Polit DF, Beck CT. Essentials of nursing research. Lippincott Williams \& Wilkins; 2013. 